\title{
Contact characteristics and factors associated with the degree of urgency among older people in emergency primary health care: a cross-sectional study
}

\author{
Lisa Marie Haraldseide ${ }^{1 *}$, Linn Solveig Sortland', Steinar Hunskaar ${ }^{1,2}$ and Tone Morken ${ }^{1}$
}

\begin{abstract}
Background: As the proportion of older people increases, so will the consumption of health services. The aim of this study was to describe the contact characteristics among older people and to identify factors associated with the degree of urgency at the Norwegian out-of-hours $(\mathrm{OOH})$ emergency primary health care services.

Methods: Inhabitants aged $\geq 70$ years who contacted the $\mathrm{OOH}$ service during 2014-2017 in seven $\mathrm{OOH}$ districts in Norway were included. We investigated the variables sex, age, time of contact, mode of contact, ICPC-2 based reason for encounter (RFE), priority degree and initial response. We also performed frequency analyses, rate calculations and a log-binomial regression.

Results: A total of 38,293 contacts were registered. The contact rate/1000 inhabitants/year was three times higher in the oldest age group ( $\geq 90$ years) compared to the youngest age group (70-74 years). Direct attendance accounted for $8.4 \%$ of the contacts and $32.8 \%$ were telephone contacts from health professionals. The most frequent RFE chapter used was "A General and unspecified" (21.0\%) which also showed an increasing rate with higher age. 6.0\% of the contacts resulted in a home visit from a doctor. Variables significantly associated with urgent priority degree were RFEs regarding cardiovascular (Relative risk (RR) 1.85; Cl 1.74-1.96), neurological (RR 1.55; Cl 1.36-1.77), respiratory (RR 1.40; Cl 1.30-1.51) and digestive (RR 1.22; Cl 1.10-1.34) issues. In addition, telephone calls from health professionals (RR 1.21; Cl 1.12-1.31), direct attendance (RR 1.13; Cl 1.04-1.22), contacts on weekdays (RR 1.13; Cl 1.06-1.20) and contacts from men (RR 1.13; Cl 1.09-1.17) were significantly associated with urgent priority degree.

Conclusions: This study provides important information about the Norwegian older inhabitants' contact with the $\mathrm{OOH}$ emergency primary health care services. There are a wide variety of RFEs, and the contact rate is high and increases with higher age. Telephone contact is most common. The $\mathrm{OOH}$ staff frequently identify older people as having "general and unspecified" reasons for encounters. $\mathrm{OOH}$ nursing staff would benefit from having screening tools and enhanced geriatric training to best support this vulnerable group when these individuals call the $\mathrm{OOH}$ service.
\end{abstract}

Keywords: Aged, Emergency medical service (EMS), International classification of primary care (ICPC), Norway, Older people, Out-of-hours, Prehospital, Primary health care, Reason for encounter, Triage

\footnotetext{
* Correspondence: liha@norceresearch.no

'National Centre for Emergency Primary Health Care, NORCE Norwegian

Research Centre, Kalfarveien 31, NO-5018 Bergen, Norway

Full list of author information is available at the end of the article
}

(C) The Author(s). 2020 Open Access This article is licensed under a Creative Commons Attribution 4.0 International License, which permits use, sharing, adaptation, distribution and reproduction in any medium or format, as long as you give appropriate credit to the original author(s) and the source, provide a link to the Creative Commons licence, and indicate if changes were made. The images or other third party material in this article are included in the article's Creative Commons licence, unless indicated otherwise in a credit line to the material. If material is not included in the article's Creative Commons licence and your intended use is not permitted by statutory regulation or exceeds the permitted use, you will need to obtain permission directly from the copyright holder. To view a copy of this licence, visit http://creativecommons.org/licenses/by/4.0/ The Creative Commons Public Domain Dedication waiver (http://creativecommons.org/publicdomain/zero/1.0/) applies to the data made available in this article, unless otherwise stated in a credit line to the data. 


\section{Background}

According to reports from the World Health Organization, the proportion of older people is increasing worldwide [1]. In 2018, $12 \%$ of the Norwegian population were 70 years or older, with an expected increase to $18 \%$ in 2040 [2]. Apart from young children, older people are among the most frequent users of emergency primary health care services [3-8].

Older patients often have multiple health problems, generally entailing polypharmacy. They are also more likely to have cognitive and functional impairments. Frailty is a common geriatric syndrome among older persons and increases in prevalence with higher age. It is related to physiological changes and a reduced reserve capacity, making older frail people vulnerable to stressors like infections, acute illness or injuries [9]. Altered vital signs represent challenges in clinical assessment among these patients [10]. Furthermore, older patients often present with diffuse symptoms or an atypical presentation of acute illness or trauma, which makes them vulnerable for possible undertriage, delayed evaluation and worsened outcome [11-19]. Another characteristic of older patients is the reluctance to seek help when needed [20]. Worries about their perception of the degree of urgency being appropriate, and about travelling at night are frequently barriers that make older people hesitant about using out-of-hours $(\mathrm{OOH})$ services, even when such use is necessary [21].

In 2019, a national quality reform for an age-friendly Norway was implemented. The goal of this reform is to contribute to better health, quality and mastery of life along with improved years of life. The reform also emphasizes that the older people should receive the health care they need [22], including home care and nursing home services, rehabilitation, regular general practitioner (RGP) and $\mathrm{OOH}$ emergency primary health care services [23]. The $\mathrm{OOH}$ services are organized differently between countries. Some countries allow direct access to hospital-based care for emergencies, while other countries have a more restricted access [24]. In Norway, the primary health care service has a gatekeeperfunction and patients may not go directly to hospital without a medical referral. The municipalities are responsible for the organization of the emergency primary health care $24 \mathrm{~h}$ a day. During daytime, patients in need of medical assistance are expected to consult RGPs. Outside opening hours, RGPs take turns working at the local $\mathrm{OOH}$ centre, which in some cases is organized within the individual municipality or in joint cooperation among multiple municipalities [25, 26]. The $\mathrm{OOH}$ services in Norway have a national telephone number (116117), enabling one to call and talk to an $\mathrm{OOH}$ nurse. In some places, one can go directly to the $\mathrm{OOH}$ centre without giving advance notice. Based on the reason for encounter (RFE) and degree of severity, the $\mathrm{OOH}$ nurse decides which response to initiate (Fig. 1).

Previous studies have reported that the most frequent RFEs resulting in telephone advice among older people are "concerns about/fear of medical treatment", "general symptoms" and "shortness of breath/dyspnoea" [27]. Furthermore, a European study reported that the most frequent chapters of ICD-10 diagnosis concerning people 65 years or older in Norway were chapter "L Musculoskeletal", "A General and unspecified" and "R Respiratory" [28]. However, knowledge is lacking on how older people utilise the $\mathrm{OOH}$ services in Norway.

The aim of this study was to investigate the contact characteristics among people 70 years and older including time and mode of contact, RFE, priority degree, and initial response, as well as identifying factors associated with urgent priority degree.

\section{Methods}

\section{Design and setting}

This cross-sectional study was based on data from the "Watchtower project" during the period 1 January 2014

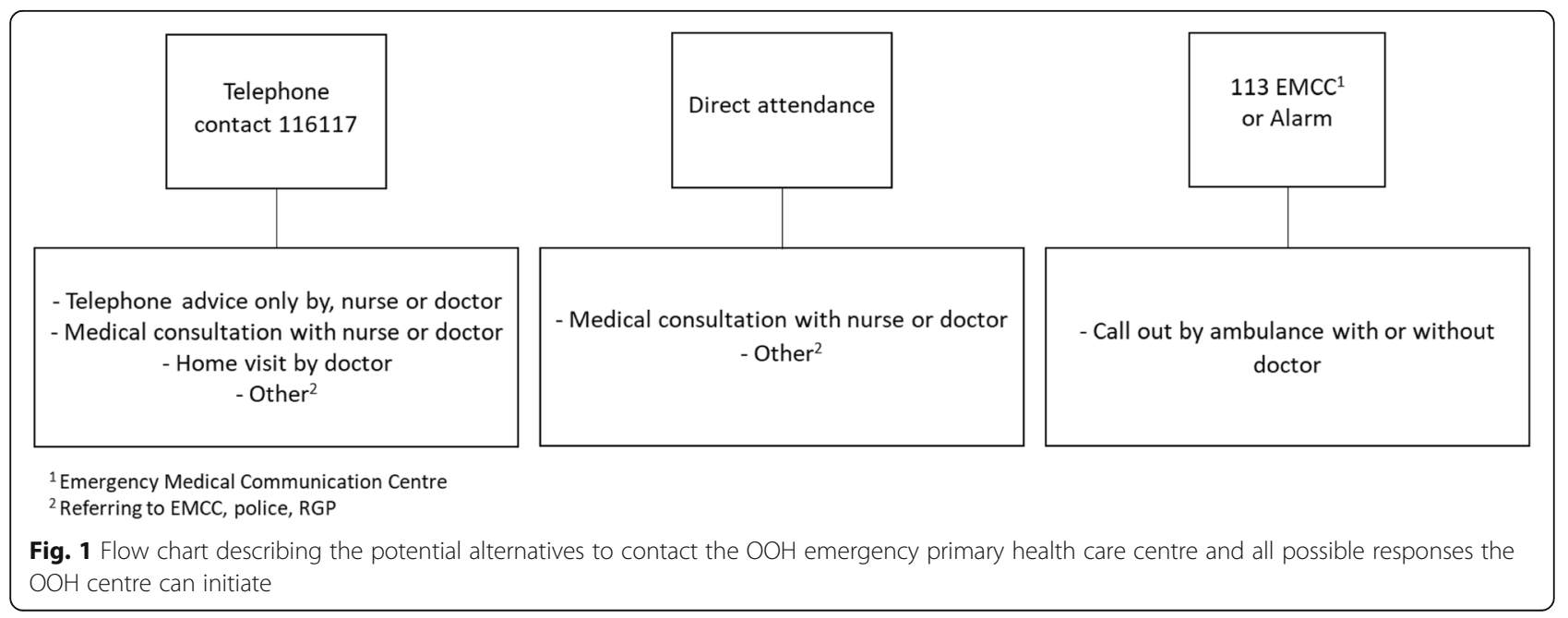


until 31 December 2017. The Watchtower project is a sentinel network of representative $\mathrm{OOH}$ emergency primary health care centres in Norway and has been collecting data on their activity since 2007. During the study period, the sentinel network consisted of seven $\mathrm{OOH}$-districts covering 18 municipalities. The total number of inhabitants from the $\mathrm{OOH}$-districts ranged from 234,480 in 2014 to 240,890 in 2017 . The average number of inhabitants corresponded to approximately $4.6 \%$ of the total Norwegian population during the study period. The Watchtower project is funded by the $\mathrm{Na}$ tional Centre for Emergency Primary Health Care, and further project details are described thoroughly elsewhere $[29,30]$.

During the four-year study period, 255,508 medical contacts were registered among all age groups, an average of 63,877 contacts per year, corresponding to 269 contacts/1000 inhabitants per year. Our study only included contacts from patients 70 years and older. The total number of inhabitants 70 years and older living in the $\mathrm{OOH}$-districts ranged from 23,353 in 2014 to 26,396 in 2017 , a yearly average of 24,751 inhabitants.

\section{Variables}

When the patient (or someone on behalf of the patient) contacted the $\mathrm{OOH}$ service, the $\mathrm{OOH}$ nurse registered the following: sex, age, day of week, time of day, mode of contact, RFE, priority degree, and first response initiated.

- Time of day: day (8 a.m. to 3.29 p.m.), evening (3.30 p.m. 10.59 p.m.) and night (11 p.m. to 7.59 a.m.). Due to the organizational model of emergency primary health care services in Norway, we excluded all daytime contacts Monday-Friday (except holidays) because during this time, the RGPs' facilities are open, and they are responsible for the patients who seek emergency medical health care.

Mode of contact: was categorized as: 1) Telephone call from patient, next of kin or caregiver, 2) Direct attendance, 3) Telephone call from health professionals, 4) Emergency Medical Communication Centre (EMCC) or alarm or 5) Other (police, social service etc.).

RFE: was registered using the International Classification of Primary Care, second edition (ICPC-2). The RFE was determined from the patient's main complaint or stated reason for contact. ICPC-2 is accepted as a mode of classifying RFEs in primary health care and has proven to be a reliable tool [31,32].

Priority degree: Each contact was assigned a colourcoded priority degree: green "non-urgent", yellow "urgent" and red "acute" in accordance with the Norwegian Index of Emergency Medical Assistance (Norwegian Index); this is a decision support tool used to determine response patterns, degree of urgency, and to provide emergency medical instruction guidance in lifesaving first aid [33].

First response initiated: was categorized as: 1) Telephone advice only, by nurse, 2) Telephone advice only, by doctor, 3) Medical consultation with a doctor, 4) Medical consultation with a nurse, 5) Call out by ambulance and doctor, 6) Home visit by doctor or 7) Other (call out by ambulance (no doctor), referral to police/ RGP).

\section{Statistical methods}

Frequencies, percentages and prevalence rates (medical contacts per 1000 inhabitants per year) were calculated for all variables. Relative risks (RR) were calculated to describe sex and age trends within the variables. To investigate variables associated with urgent priority degree, we performed a log-binomial regression analysis in a two-step manner. The dependent variable was degree of urgency, dichotomized into non-urgent (green) and urgent/acute (yellow/red). The independent variables included were sex, time of day, weekdays (Monday 8 a.m. to Friday 3.29 p.m.) vs. weekend (Friday 3.30 p.m. to Monday 7.59 a.m.), the different modes of contact (telephone from patient, next of kin, caregiver, telephone from health professionals and direct attendance) and RFE by ICPC- 2 chapter. RR, 95\% confidence interval (CI) and $p$-values were estimated. To account for possible dependence within each $\mathrm{OOH}$-district, we used robust standard error estimates. First, each independent variable listed above was tested in an unadjusted model; second, the variables considered significant were applied together in an adjusted model. In the adjusted model, we used iterated, reweighted least-squares optimization of the deviance. Due to problems with convergence, we could not include the variable time of day in the adjusted model. The reported RRs, CIs and $p$-values for this variable were adjusted for a modified RFE-variable in addition to the other variables (see Table 4).

In our data material, $9.9 \%$ of the cases had missing ICPC-2 codes (Table 1, RFE unknown). For the other variables, missing data were insignificant. No imputation methods for missing values were used.

IBM SPSS Statistics 25 and StataSE16 were used to analyse the data, and the significance level was set to $\alpha=0.05$.

\section{Ethics}

This study is part of the Watchtower project and has been approved by the Norwegian Centre for Research Data (SAK 31590). All data are anonymized, no patient identifiable data were recorded at any time, hence there was no need for informed consent from participants. The Regional Committee for Medical and Health 
Table $1 \mathrm{OOH}$ contact characteristics of patients 70 years and older $(n=38,293)$

\begin{tabular}{|c|c|c|c|}
\hline Contact characteristics & $\mathrm{n}$ & $(\%)$ & Rate $^{\mathrm{a}}$ \\
\hline \multicolumn{4}{|l|}{ Age groups } \\
\hline 70-74 years & 9353 & $(24.4)$ & 253 \\
\hline 75-79years & 8253 & (21.6) & 328 \\
\hline $80-84$ years & 8113 & $(21.2)$ & 458 \\
\hline $85-89$ years & 7088 & (18.5) & 594 \\
\hline$\geq 90$ years & 5486 & (14.3) & 769 \\
\hline \multicolumn{4}{|l|}{ Sex } \\
\hline Women & 22,140 & $(57.8)$ & 401 \\
\hline Men & 16,146 & $(42.2)$ & 369 \\
\hline Sex unknown & 7 & $(0.0)$ & 0 \\
\hline \multicolumn{4}{|l|}{ Time of day } \\
\hline Daytime (08:00-15:29) ${ }^{\mathrm{b}}$ & 12,089 & (31.6) & 122 \\
\hline Evening (15:30-22:59) & 20,025 & (52.3) & 202 \\
\hline Night (23:00-07:59) & 6179 & $(16.1)$ & 62 \\
\hline \multicolumn{4}{|l|}{ Day of week } \\
\hline Monday & 3989 & $(10.4)$ & 40 \\
\hline Tuesday & 3527 & $(9.2)$ & 36 \\
\hline Wednesday & 3641 & $(9.5)$ & 37 \\
\hline Thursday & 3831 & $(10.0)$ & 39 \\
\hline Friday & 4248 & $(11.1)$ & 43 \\
\hline Saturday & 10,214 & (26.7) & 103 \\
\hline Sunday & 8843 & $(23.1)$ & 89 \\
\hline \multicolumn{4}{|l|}{ Mode of contact } \\
\hline $\begin{array}{l}\text { Telephone from patient, } \\
\text { next of kin, caregiver }\end{array}$ & 19,896 & $(52.0)$ & 201 \\
\hline $\begin{array}{l}\text { Telephone from health } \\
\text { professionals }\end{array}$ & 12,483 & $(32.8)$ & 126 \\
\hline Direct attendance & 3198 & $(8.4)$ & 32 \\
\hline EMCC c/alarm & 2513 & (6.6) & 25 \\
\hline Other (police, social service) & 198 & $(0.5)$ & 2 \\
\hline Mode of contact unknown & 5 & $(0.0)$ & 0 \\
\hline \multicolumn{4}{|l|}{ Reason for encounter (ICPC-2 chapter) } \\
\hline General and unspecified (A) & 8109 & $(21.2)$ & 82 \\
\hline Musculoskeletal (L) & 5189 & (13.6) & 52 \\
\hline Respiratory (R) & 4937 & $(12.9)$ & 50 \\
\hline Urological (U) & 3557 & (9.3) & 36 \\
\hline Digestive (D) & 3354 & (8.8) & 34 \\
\hline Cardiovascular (K) & 2436 & $(6.4)$ & 25 \\
\hline Skin (S) & 2172 & $(5.7)$ & 22 \\
\hline Neurological (N) & 1526 & $(4.0)$ & 15 \\
\hline Psychological (P) & 1218 & $(3.2)$ & 12 \\
\hline Eye $(F)$ & 714 & (1.9) & 7 \\
\hline Endocrine/metabolic/nutrition (T) & 480 & $(1.3)$ & 5 \\
\hline Other chapters ${ }^{d}$ & 797 & $(2.1)$ & 8 \\
\hline
\end{tabular}

Table $1 \mathrm{OOH}$ contact characteristics of patients 70 years and older ( $n=38,293)$ (Continued)

\begin{tabular}{llll}
\hline Contact characteristics & $\mathrm{n}$ & $(\%)$ & Rate $^{\mathrm{a}}$ \\
\hline Reason for encounter unknown & 3804 & $(9.9)$ & 39 \\
Priority degree & & & \\
$\quad$ Green, not urgent & 23,110 & $(60.4)$ & 233 \\
$\quad$ Yellow, urgent & 12,574 & $(32.8)$ & 127 \\
$\quad$ Red, acute & 2554 & $(6.7)$ & 26 \\
Priority degree unknown & 55 & $(0.1)$ & 0 \\
Initial response & & & \\
Medical consultation by doctor & 18,530 & $(48.4)$ & 187 \\
$\quad$ Telephone advice only, by doctor & 6764 & $(17.7)$ & 68 \\
$\quad$ Telephone advice only, by nurse & 6546 & $(17.1)$ & 66 \\
$\quad$ Home visit by doctor & 2296 & $(6.0)$ & 23 \\
Call out by ambulance and doctor & 1819 & $(4.8)$ & 18 \\
$\quad \begin{array}{l}\text { Other (call out by ambulance } \\
\text { (no doctor)/ref. to police) }\end{array}$ & 1790 & $(4.7)$ & 18 \\
$\quad \begin{array}{l}\text { Medical consultation by nurse } \\
\text { Initial response unknown }\end{array}$ & 450 & $(1.2)$ & 5 \\
\hline
\end{tabular}

${ }^{a}$ Rate per 1000 inhabitants per year; ${ }^{b}$ Saturdays, Sundays, Holidays; ${ }^{c}$ EMCC: Emergency Medical Communication Centre; ${ }^{d}$ Ear $(H)$, Blood (B), Male genital $(\mathrm{Y})$, Female genital (X), Social problems (Z) Pregnancy and family planning (W)

Research Ethics did not consider it necessary to assess the study for approval (2012/1094/REC West).

\section{Results}

\section{Inhabitants and contact characteristics}

During the four-year study period, a total of 38,293 contacts from patients 70 years and older were registered, an average of 9573 contacts each year (387 contacts/ 1000 inhabitants 70 years and older per year). The absolute number of contacts decreased with higher age, but the rate was three times higher in the oldest age group ( $\geq 90$ years) compared to the youngest age group (70-74 years) (769 vs. 253 contacts/1000 inhabitants per year) (Table 1).

The mean age was 81 years (range 70 to 107 years), and women had the highest contact rates compared with men (401 vs. 369). Saturday was the day with highest percentage of contacts (26.7\%), followed by Sunday (23.1\%). Additionally, we found that Monday (10.4\%) and Friday (11.1\%) had a slightly higher number of contacts than the remaining weekdays $(9.2-10.0 \%)$. Over half $(52.0 \%)$ of the contacts came from patients, next of kin or caregiver by telephone while one-third $(32.8 \%)$ of the contacts were telephone from health professionals (Table 1). Contacts by telephone from health professionals were seven times more common among patients 85 years and older compared to patients between 70 and 74 years (see Additional file 2). The proportion of direct attendance was low (8.4\%) compared to the telephone 
contacts (Table 1), and it decreased even further with higher age (see Additional file 2). The majority of the contacts $(60.4 \%)$ were set to green (not urgent) priority degree, followed by yellow (urgent) (32.9\%) and red (acute) (6.7\%) (Table 1). We also found a higher rate among women compared with men in contacts resulting in green priority degree (251 vs. 211) (see Additional file 1).

\section{RFE by ICPC-2 chapter and code}

The most frequent RFE within the ICPC-2 chapters was "A General and unspecified" (21.2\%) followed by chapter "L Musculoskeletal" (13.6\%) and R "Respiratory" (12.9\%). The chapters "U Urological" and "D Digestive" were also relatively common RFEs (Table 1). "A General and unspecified" was the ICPC-2 chapter that increased the most with higher age (compared with chapter "L" and "R") (see Additional file 1). The relative risk (RR) of contacting the $\mathrm{OOH}$ service with an "A General and unspecified" RFE was 5.2 (men) and 4.4 (women) times higher in persons 90 years and older compared with persons between 70 and 74 years of age. Women with contacts from the "L Musculoskeletal" chapter had a higher rate compared with men (60 vs. 42) (see Additional file 1).
We registered 493 different ICPC-2 codes (RFEs). Table 2 presents the 20 most frequent RFEs, which added up to $46.3 \%$ of all the contacts. The most common RFE were "R02 Shortness of breath/dyspnoea" (5.0\%), followed by "D01 Abdominal pain/cramps general" (3.8\%).

\section{Most frequent RFE and first initial response}

Almost half $(48.4 \%)$ of the contacts resulted in a medical consultation with a doctor. The proportion of contacts that resulted in telephone advice from a nurse and doctor were about the same, while home visits by a doctor were infrequent (6.0\%) (Table 1). We also found a higher rate among women compared to men regarding telephone advice from a nurse and doctor (147 vs. 119) (see Additional file 2). When the first response initiated was a home visit by a doctor, the RR was almost 14 times higher in patients 90 years and older compared to patients between 70 and 74 years in both men and women (see Additional file 2).

Table 3 shows the most common RFEs by first initial response. The most common RFEs that led to a medical consultation with a doctor were "R02 Shortness of breath" (5.3\%) and "D01 Abdominal pain/cramps general" (4.7\%). "A13 Concerns about/fear of medical treatment" (8.0\%) was the RFE that received telephone advice

Table 2 The most frequent RFEs by ICPC-2 codes $(n=34,489)$

\begin{tabular}{|c|c|c|c|c|}
\hline ICPC-2 code & ICPC-2 code name & $n$ & $(\%)$ & Rate $^{a}$ \\
\hline R02 & Shortness of breath/dyspnoea & 1728 & $(5.0)$ & 17 \\
\hline D01 & Abdominal pain/cramps general & 1318 & (3.8) & 13 \\
\hline U71 & Cystitis/urinary infection other & 1189 & (3.4) & 12 \\
\hline A13 & Concern about/fear of medical treatment & 1095 & $(3.2)$ & 11 \\
\hline A11 & Chest pain & 1001 & $(2.9)$ & 10 \\
\hline A03 & Fever & 930 & $(2.7)$ & 9 \\
\hline A29 & General symptom/complaint other & 828 & $(2.4)$ & 8 \\
\hline S18 & Laceration/cut & 806 & $(2.3)$ & 8 \\
\hline $\mathrm{A} 28$ & Limited function/disability & 745 & $(2.2)$ & 7 \\
\hline U29 & Urinary symptom/complaint other & 717 & $(2.1)$ & 7 \\
\hline L02 & Back symptom/complaint & 651 & $(1.9)$ & 7 \\
\hline R05 & Cough & 628 & $(1.8)$ & 6 \\
\hline L13 & Hip symptom/complaint & 621 & $(1.8)$ & 6 \\
\hline A96 & Death & 604 & $(1.8)$ & 6 \\
\hline N17 & Vertigo/dizziness & 581 & $(1.7)$ & 6 \\
\hline R81 & Pneumonia & 551 & $(1.6)$ & 6 \\
\hline L17 & Foot/toe symptom/complaint & 538 & (1.6) & 5 \\
\hline L14 & Leg/thigh symptom/complaint & 494 & $(1.4)$ & 5 \\
\hline R29 & Respiratory symptom/complaint & 478 & $(1.4)$ & 5 \\
\hline \multirow[t]{2}{*}{ A97 } & No disease & 469 & (1.4) & 5 \\
\hline & Other RFEs & 18,517 & $(53.7)$ & 187 \\
\hline
\end{tabular}

\footnotetext{
${ }^{a}$ Rate per 1000 inhabitants 70 years and older per year
} 
Table 3 The most frequent RFEs by ICPC-2 codes and initial response; medical consultation doctor, telephone advice, home visit by doctor, call out by ambulance and doctor $(n=32,386)$

\begin{tabular}{|c|c|c|c|c|}
\hline ICPC-2 code & Initiated response \& ICPC-2 code name & $n$ & $(\%)$ & Rate $^{\mathrm{a}}$ \\
\hline \multicolumn{5}{|c|}{ Medical consultation doctor $(n=16,862)$} \\
\hline R02 & Shortness of breath/dyspnoea & 898 & $(5.3)$ & 9 \\
\hline D01 & Abdominal pain/cramps general & 786 & $(4.7)$ & 8 \\
\hline S18 & Laceration/cut & 627 & $(3.7)$ & 6 \\
\hline U71 & Cystitis/urinary infection & 604 & (3.6) & 6 \\
\hline A11 & Chest pain & 491 & $(2.9)$ & 5 \\
\hline \multirow[t]{2}{*}{ A03 } & Fever & 440 & $(2.6)$ & 4 \\
\hline & Other & 13,016 & $(77.2)$ & 131 \\
\hline \multicolumn{5}{|c|}{ Telephone advice only $(n=11,856)$} \\
\hline A13 & Concern about/fear of medical treatment & 948 & $(8.0)$ & 10 \\
\hline A28 & Limited function/disability & 581 & $(4.9)$ & 6 \\
\hline U71 & Cystitis/urinary infection & 495 & $(4.2)$ & 5 \\
\hline A29 & General symptom/complaint & 376 & $(3.2)$ & 4 \\
\hline R02 & Shortness of breath/dyspnoea & 367 & $(3.1)$ & 4 \\
\hline \multirow[t]{2}{*}{ D01 } & Abdominal pain/cramps general & 358 & $(3.0)$ & 4 \\
\hline & Other & 8731 & (73.6) & 88 \\
\hline \multicolumn{5}{|c|}{ Home visit by doctor $(n=2043)$} \\
\hline A96 & Death & 274 & $(13.4)$ & 3 \\
\hline R02 & Shortness of breath/dyspnoea & 155 & $(7.6)$ & 1 \\
\hline R81 & Pneumonia & 121 & $(5.9)$ & 1 \\
\hline A03 & Fever & 106 & $(5.5)$ & 1 \\
\hline A29 & General symptom/complaint other & 66 & $(3.2)$ & 1 \\
\hline \multirow[t]{2}{*}{ D01 } & Abdominal pain/cramps general & 56 & $(2.7)$ & 1 \\
\hline & Other & 1265 & $(61.7)$ & 13 \\
\hline \multicolumn{5}{|c|}{ Call out by ambulance and doctor $(n=1625)$} \\
\hline A11 & Chest pain NOS & 252 & $(15.0)$ & 3 \\
\hline R02 & Shortness of breath/dyspnoea & 159 & $(9.8)$ & 2 \\
\hline K01 & Heart pain & 149 & $(9.2)$ & 2 \\
\hline K90 & Stroke/cerebrovascular accident & 108 & $(6.7)$ & 1 \\
\hline D01 & Abdominal pain/cramps general & 59 & $(3.7)$ & 1 \\
\hline \multirow[t]{2}{*}{ L13 } & Hip symptom/complaint & 51 & $(3.2)$ & 1 \\
\hline & Other & 847 & $(52.4)$ & 9 \\
\hline
\end{tabular}

${ }^{\mathrm{a}}$ Rate per 1000 inhabitants 70 years and older per year

from a nurse or doctor most frequently. In home visits by a doctor, the RFE code "A96 Death" (13.3\%) had almost twice as many contacts compared to "R02 Shortness of breath/dyspnoea" (7.6\%).

\section{Variables associated with urgent priority degree}

The results from the log-binomial regression model are presented in Table 4. The unadjusted model found all variables to be significantly associated with urgent priority degree $(p<0.001)$.

In the adjusted model, the RFE chapters "K Cardiovascular", "N Neurological", "R Respiratory" and "D Digestive" were strongest associated with urgent priority degree (all $p<0.001$ ). The RR for urgent priority degree was $85 \%$ higher when the patient had a contact within chapter "K Cardiovascular" compared to "A General and unspecified". The RRs for the chapters "N Neurological", "R Respiratory" and "D Digestive" were 55, 40 and $22 \%$, respectively. The RR was $13 \%$ higher when the patients attended the $\mathrm{OOH}$ centre directly $(p=0.003)$ and $21 \%$ higher when a health professional called the $\mathrm{OOH}$ centre $(p<0.001)$ (compared with telephone from patient, next to kin or caregiver). The $\mathrm{RR}$ for receiving an urgent priority degree was 13\% 
Table 4 Unadjusted and adjusted log-binomial regression model for urgent priority by; sex, age, time of day, week, mode of contact and RFE by ICPC-2 chapter

\begin{tabular}{|c|c|c|c|c|c|c|}
\hline \multirow[t]{2}{*}{ Variables } & \multirow[t]{2}{*}{$\mathrm{n}$} & \multirow[t]{2}{*}{ (\%) } & Unadjusted & \multirow[t]{2}{*}{$p$ value } & Adjusted & \multirow[t]{2}{*}{$p$ value } \\
\hline & & & RR $(95 \%$ Cl) & & RR (95\% Cl) & \\
\hline \multicolumn{7}{|l|}{ Sex } \\
\hline Women & 8248 & (37.3) & Ref. & & Ref. & \\
\hline Men & 6875 & $(42.7)$ & $1.14(1.11-1.18)$ & $<0.001$ & $1.13(1.09-1.17)$ & $<0.001$ \\
\hline \multicolumn{7}{|l|}{ Age groups } \\
\hline $70-74$ & 3586 & (38.4) & Ref. & & Ref. & \\
\hline $75-79$ & 3285 & (39.9) & $1.04(1.01-1.07)$ & 0.018 & $1.05(1.01-1.8)$ & 0.010 \\
\hline $80-84$ & 3143 & $(38.8)$ & $1.01(0.96-1.06)$ & 0.698 & $0.99(0.93-1.05)$ & 0.718 \\
\hline $85-89$ & 2917 & $(41.2)$ & $1.07(1.03-1.12)$ & 0.001 & $1.08(1.02-1.13)$ & 0.007 \\
\hline $90+$ & 2197 & $(40.1)$ & $1.04(1.01-1.08)$ & 0.011 & $1.06(1.01-1.10)$ & 0.012 \\
\hline \multicolumn{7}{|l|}{ Time of day } \\
\hline Day 08:00-15:29 & 4019 & (33.3) & $0.83(0.80-0.87)$ & $<0.001$ & $0.86(0.82-0.90)$ & $<0.001^{*}$ \\
\hline Evening 15:30-22:59 & 8044 & $(40.2)$ & Ref. & & Ref. & \\
\hline Night 23:00-07:59 & 3265 & $(49.7)$ & $1.24(1.12-1.37)$ & $<0.001$ & $1.22(1.12-1.32)$ & $<0.001 *$ \\
\hline \multicolumn{7}{|l|}{ Week } \\
\hline Weekday & 6602 & $(43.2)$ & $1.16(1.08-1.26)$ & $<0.001$ & $1.13(1.06-1.20)$ & $<0.001$ \\
\hline Weekend & 8526 & (37.1) & Ref. & & Ref. & \\
\hline \multicolumn{7}{|l|}{ Mode of contact } \\
\hline Telephone patient, next of kin, caregiver & 6772 & $(34.1)$ & Ref. & & Ref. & \\
\hline Direct attendance & 1226 & $(38.4)$ & $1.13(1.05-1.21)$ & 0.001 & $1.13(1.04-1.22)$ & 0.003 \\
\hline Telephone health professionals & 5173 & $(41.5)$ & $1.22(1.12-1.32)$ & $<0.001$ & $1.21(1.12-1.31)$ & $<0.001$ \\
\hline \multicolumn{7}{|l|}{ RFE by ICPC-2 chapter } \\
\hline (A) General and unspecified & 3064 & (37.9) & Ref. & & Ref. & \\
\hline (L) Musculoskeletal & 1992 & $(38.4)$ & $1.01(0.93-1.10)$ & 0.754 & $1.13(1.02-1.25)$ & 0.015 \\
\hline (R) Respiratory & 2373 & $(48.1)$ & $1.27(1.19-1.35)$ & $<0.001$ & $1.40(1.30-1.51)$ & $<0.001$ \\
\hline (U) Urological & 1028 & (28.9) & $0.76(0.61-0.96)$ & 0.022 & $0.86(0.68-1.10)$ & 0.235 \\
\hline (D) Digestive & 1400 & $(41.8)$ & $1.10(1.02-1.19)$ & 0.009 & $1.22(1.10-1.34)$ & $<0.001$ \\
\hline (K) Cardiovascular & 1616 & $(66.4)$ & $1.75(1.63-1.89)$ & $<0.001$ & $1.85(1.74-1.96)$ & $<0.001$ \\
\hline (S) Skin & 672 & (31.0) & $0.82(0.74-0.91)$ & $<0.001$ & $0.91(1.81-1.02)$ & 0.091 \\
\hline (N) Neurological & 827 & $(54.3)$ & $1.43(1.26-1.63)$ & $<0.001$ & $1.55(1.36-1.77)$ & $<0.001$ \\
\hline (P) Psychological & 341 & $(28.0)$ & $0.74(0.67-0.81)$ & $<0.001$ & $0.78(0.71-0.86)$ & $<0.001$ \\
\hline (F) Eye & 170 & $(23.8)$ & $0.63(0.56-0.71)$ & $<0.001$ & $0.75(0.66-0.85)$ & $<0.001$ \\
\hline (T) Endocrine/metabolic/nutrition & 164 & $(34.2)$ & $0.90(0.71-1.15)$ & 0.416 & $0.93(0.75-1.15)$ & 0.507 \\
\hline Other chapters ${ }^{a}$ & 231 & $(29.1)$ & $0.77(0.68-0.87)$ & $<0.001$ & $0.85(0.78-0.94)$ & 0.001 \\
\hline
\end{tabular}

Log-binominal regression analyses using women, age group 70-74, evening 15:30-22:59, weekend, telephone from patient or next of kin or caregiver and ICPC-2 chapter "A General and unspecified" as reference; We used clustered standard errors to adjust for possible dependence in the seven OOH-districts; Significant values are marked as bold; ${ }^{a} \operatorname{Ear}(\mathrm{H})$, Blood (B), Male genital (Y), Female genital (X), Social problems (Z) Pregnancy and family planning (W).*Due to model limitations with too many variables with multiple categories in the adjusted model, the variable "Time of day" was excluded from the adjusted analysis. The reported RR, Cl and p-values for this variable were adjusted for a modified RFE-variable (with the categories "A General and unspecified", "L Musculoskeletal", "R Respiratory" and "Other chapters") in addition to the other variables

higher when both men $(p<0.001)$ contacted the $\mathrm{OOH}$ service (compared with women) and when the contact happened on a weekday (compared to weekends). Lastly, within the age groups $75-79$ years $(p=0.010), 85-89$ years $(p=0.007)$ and 90 years and older $(p=0.012)$ the RRs for receiving an urgent priority were $5-8 \%$ higher (compared with 70-74 years); hence we found no particular increase in urgent priority degree with higher age.

\section{Discussion}

The contact rate increased with higher age. Telephone contact from health professionals calling on behalf of 
the patient was found to be a common mode of contact, especially for those 85 years and older. In addition, the rate of direct attendance was low. The most common RFE by chapter was "A General and unspecified", and the rate increased with higher age. Home visits by a doctor were few, but the rate increased considerably for patients 85 years of age or older. Lastly, variables significantly associated with urgent priority degree were RFEs regarding cardiovascular, neurological, respiratory and digestive issues in addition to telephone calls from health professionals, direct attendance, contacts on weekdays and contacts from men.

The overall contact rate in our study population was $387 / 1000$ inhabitants, much higher than the overall rate for the whole population (269/1000). The rate increased significantly with higher age. Similar trends were found in studies investigating telephone contacts from older people at the $\mathrm{OOH}$ service in England and Scotland [5], and visits to the emergency department in Chicago [4]. The increased utilization of $\mathrm{OOH}$ services could be explained by higher age itself, but is more likely due to factors such as frailty and multimorbidity $[34,35]$.

The majority of contacts came by telephone and almost one-third were calls from health professionals. This illustrates that older people contact the $\mathrm{OOH}$ services indirectly, and that the $\mathrm{OOH}$ nurse frequently communicates with a person calling on behalf of the patient. A recently published qualitative study from Ireland reported that older people find it difficult to contact the $\mathrm{OOH}$ services when they become ill. Concerns about transportation and having to ask family members or neighbours for help, especially at night, were associated with a reluctance to seek help [20]. Older persons may therefore find it less problematic to contact the $\mathrm{OOH}$ service by telephone instead of going in person.

We found a high number (493) of different RFEs. A Danish study found 392 different RFEs among telephone contacts in all age groups [36]. The large number in our study shows that older people have broadly varied symptoms, conditions, and issues. Furthermore, the most common RFE by chapter was "A General and unspecified", and the proportion increased with higher age. A similar result was found in an Australian study [37], but the results were from general practice and not an $\mathrm{OOH}$ setting, which may affect the sample of patients and RFEs. Chapter "A General and unspecified" has previously proven to be common among all age groups [28]. However, as the rate of this RFE increased among older people, one might question if this age group is more difficult to interpret due to diffuse symptoms and complaints. We therefore specifically investigated some single RFEs within the chapter "A General and unspecified".
The most common RFE code within the chapter "A General and unspecified" was "A13 Concern about/fear of medical treatment". Our study material cannot substantiate what these $8 \%$ of the contacts involved, but it may be related to polypharmacy or lack of health literacy. Data from the Norwegian Prescription Database showed that more than half of all registered women and men 65 to 74 years old had five or more prescriptions in 2016 and the proportion increased considerably with higher age [38]. Moreover, studies have shown that health literacy decreases with aging [39], and that physicians tend to overestimate patients' literacy level [40]. This underscores that physicians need to be aware of the patient's literacy level, and target communication accordingly, especially when it comes to new prescriptions or changes in medication.

The ICPC-2 codes "A28 Limited function/disability" and "A29 General symptom/complaint" were also common RFEs in our study. Combined, these codes accounted for the highest proportion of telephone advice responses. Several studies have reported a moderate to high frequency of atypical presentation in acute illness among older people presenting to emergency departments [11-19]. "A28 Limited function/disability" and "A29 General symptom/complaint" could possibly fit such a term. Previous studies have included terms like "decreased general condition" [13], "non-specific complaints" $[11,18]$ or "general weakness" [19] in atypical presentation. Several studies have found that such diffuse and non-specific symptoms in many cases represent underlying serious illness, like stroke, pneumonia, or ischemic heart disease [12, 14, 18, 19].

Contacts resulting in home visits by doctors were few in our study, although the rate increased with higher age. Other studies have also found an increase in home visits among older people [5, 7]. In the past three decades, there has been a steady decrease in the number of home visits [41]. Simultaneously, there has been a trend towards fewer and larger $\mathrm{OOH}$ districts. The smallest $\mathrm{OOH}$ centres are those that perform home visits most often [3, 41], and long distances to the $\mathrm{OOH}$ centre affects Norwegian inhabitants' utilization of the $\mathrm{OOH}$ centres [42]. Therefore, the municipalities must facilitate for home visits among the older people when organizing their service. By doing so, the frailest patients for whom it is undesirable and potentially harmful to travel to the $\mathrm{OOH}$ centres, can receive the help they need.

Direct attendance was associated with urgent priority degree. This fits well with findings from a qualitative study investigating nurse practitioners triage decisions. The study found that the patient's physical appearance and "how stable and unstable they look" were cues that strongly affected their triage decision [43]. 
Contacts from men were significantly associated with urgent priority degree, in line with a study from the Netherlands [44]. A possible explanation for our finding may be that $\mathrm{OOH}$-nurses generally perceive men as more urgent cases than women. A study of triage decisions found that nurses were more likely to consider the situation as significant when men presented with complaints suggesting acute myocardial infarction [43]. The gender differences in priority degree may also be explained by gender differences in symptom presentation. It has previously been reported that women tend to present more often with atypical symptoms [45] which may result in under-triage [14]. However, the gender effect on symptom presentation is debatable, and authors have reported that symptom presentation is affected by other factors [45], and not by gender itself. Our data does not contain information about the presentation form, only one ICPC- 2 code per contact. Therefore, future studies should include symptom presentation when investigating the $\mathrm{OOH}$ nurses' triage decisions to elaborate the gender differences among older people.

An educational consequence of our findings may be that specific training of $\mathrm{OOH}$ nurses in the variety of symptoms and presentations of older people should be strengthened. In addition, there could be more incorporation of older persons' characteristics in decision support tools. It would also be of benefit for the $\mathrm{OOH}$ nurses if simple screening tools were available to detect older frail patients by telephone, which unfortunately is not the case at the $\mathrm{OOH}$ emergency primary health care services in Norway at the present time.

\section{Strengths and limitations}

To our knowledge, studies of $\mathrm{OOH}$ contact characteristics and factors associated with the degree of urgency among the older population in Norway have not been conducted previously. Our study also has a high number of registrations. We consider $9 \%$ missing ICPC-2 codes as a low percentage. One possible reason for lacking data might be difficulties in deciding the RFE among older people, but a previous study that analysed the same material found that there were no age differences in lacking ICPC-2 codes [30]. We used both adjusted and unadjusted models in the log binomial regression analyses in order to take into account the effects of other factors that may have been missed in an unadjusted model alone.

Our data sample has been collected from the "Watchtower project" which was initiated in 2006. The project was designed to be representative of the $\mathrm{OOH}$ services in Norway by considering the population size, degree of population change, age and sex composition, degree of centrality, type of business in the municipalities, municipal economy and income level. Representativeness has been validated previously [25]. Nevertheless, we cannot exclude the possibility that changes in the seven $\mathrm{OOH}$ districts in the subsequent years may have resulted in a lower degree of representativity.

Our data do not include variables about frailty, multimorbidity, functional level or socioeconomic aspects. We registered contacts, not patients. We therefore do not know how many times the same patient has contacted the $\mathrm{OOH}$ service during the study period. The nurses only register one symptom per patient, and this may be problematic given that older people often have multiple symptoms and a possibly complex disease composition.

\section{Conclusions}

This study provides important information about the Norwegian older inhabitants' contact with the $\mathrm{OOH}$ emergency primary health care services. There are a wide variety of RFEs, and the contact rate is high and increases with higher age. Telephone contact is most common. The $\mathrm{OOH}$ staff frequently identify older people as having "general and unspecified" reasons for encounters. $\mathrm{OOH}$ nursing staff would benefit from having screening tools and enhanced geriatric training to best support this vulnerable group when these individuals call the $\mathrm{OOH}$ service.

\section{Supplementary information}

Supplementary information accompanies this paper at https://doi.org/10. 1186/s12913-020-05219-0.

Additional file 1. Age and sex differences within RFE by ICPC-2 chapter, time of day and priority degree.

Additional file 2. Age and sex differences within mode of contact and first response initiated.

\section{Abbreviations}

EMCC: Emergency Medical Communication Centre; ICPC-2: International Classification of Primary Care 2nd edition; ICD-10: International Classification of Diseases 10th revision; $\mathrm{OOH}$ : Out-of-hours; RFE: Reason for encounter; RGP: Regular general practitioner; RR: Relative risk

\section{Acknowledgements}

The authors would like to thank Ole Johan Eikeland for help with data extraction and Valborg Baste for help with the statistical analyses. We also want to thank the employees who register the $\mathrm{OOH}$ contacts in the Watchtower project.

\section{Authors' contributions}

$\mathrm{LMH}$ drafted and revised the article and contributed to the design, statistical analyses and interpretation of the results. LSS drafted the methods, contributed in the interpretation of the results, and revised the article. SH and TM contributed to the design, interpretation of the results and revision of the article for intellectual content. All authors have approved the final version.

\section{Funding}

Project by the National Centre for Emergency Primary Health Care, NORCE Norwegian Research Centre, funded by the Norwegian Directorate of Health. The funders had no role in any part of this article. 


\section{Availability of data and materials}

Due to the approvals from the Regional committee for Medical and Health Research Ethics and the Privacy ombudsman for research, the data are not currently available, but are available from the corresponding author on reasoned/justified request.

\section{Ethics approval and consent to participate}

This study is part of the Watchtower project and has been approved by the Norwegian Centre for Research Data (SAK 31590). All data are anonymized, no patient identifiable data were recorded at any time, hence there was no need for informed consent from participants. The Regional Committee for Medical and Health Research Ethics did not consider it necessary to assess the study for approval (2012/1094/REC West).

\section{Consent for publication}

Not applicable.

\section{Competing interests}

The authors declare that they have no competing interests.

\section{Author details}

${ }^{1}$ National Centre for Emergency Primary Health Care, NORCE Norwegian Research Centre, Kalfarveien 31, NO-5018 Bergen, Norway. ${ }^{2}$ Department of Global Public Health and Primary Care, University of Bergen, Bergen, Norway.

\section{Received: 27 January 2020 Accepted: 13 April 2020}

\section{Published online: 22 April 2020}

\section{References}

1. Anonymous. Study: older patients vulnerable to functional decline following ED visit. Hosp Case Manag. 2017;25(6):86-7.

2. Statistics Norway: National Census Statistics; 2019. [Available from: https:// www.ssb.no/befolkning]. Accessed 15 Apr 2020.

3. Eikeland OJ FS, Raknes G, Hunskår S. Vakttårnprosjektet. Epidemiologiske data frå legevakt. Samlerapport for 2018. Rapport nr. 3-2019. The Watchtower project. Epidemiological data from $\mathrm{OOH}$ services 2018]. Bergen: National Centre for emergency primary health care, NORCE Helse 2018. 2018.

4. Shah MN, Rathouz PJ, Chin MH. Emergency department utilization by noninstitutionalized elders. Acad Emerg Med Off J Soc Acad Emerg Med. 2001;8(3):267-73.

5. Salisbury C, Trivella M, Bruster S. Demand for and supply of out of hours care from general practitioners in England and Scotland: observational study based on routinely collected data. BMJ (Clinical research ed). 2000; 320(7235):618-21.

6. Aminzadeh F, Dalziel WB. Older adults in the emergency department: a systematic review of patterns of use, adverse outcomes, and effectiveness of interventions. Ann Emerg Med. 2002;39(3):238-47.

7. Margas G, Windak A, Tomasik T. Utilization of the out of hours service in Poland: an observational study from Krakow. BMC Health Serv Res. 2008;8: 212.

8. Albert M, McCaig LF, Ashman JJ. Emergency department visits by persons aged 65 and over: United States, 2009-2010. NCHS Data Brief. 2013(130):1-8.

9. Fried LP, Ferrucci L, Darer J, Williamson JD, Anderson G. Untangling the concepts of disability, frailty, and comorbidity: implications for improved targeting and care. J Gerontol A Biol Sci Med Sci. 2004;59(3):255-63.

10. Chester JG, Rudolph JL. Vital signs in older patients: age-related changes. J Am Med Dir Assoc. 2011;12(5):337-43.

11. Wachelder JJH, Stassen PM, Hubens L, Brouns SHA, Lambooij SLE, Dieleman $J P$, et al. Elderly emergency patients presenting with non-specific complaints: characteristics and outcomes. PLoS One. 2017;12(11):e0188954.

12. Hofman MR, van den Hanenberg F, Sierevelt IN, Tulner CR. Elderly patients with an atypical presentation of illness in the emergency department. Neth J Med. 2017;75(6):241-6.

13. Djarv T, Castren M, Martenson L, Kurland L. Decreased general condition in the emergency department: high in-hospital mortality and a broad range of discharge diagnoses. Eur J Emerg Med. 2015;22(4):241-6.

14. Rutschmann OT, Chevalley T, Zumwald C, Luthy C, Vermeulen B, Sarasin FP. Pitfalls in the emergency department triage of frail elderly patients without specific complaints. Swiss Med Wkly. 2005;135(9-10):145-50.
15. Limpawattana P, Phungoen P, Mitsungnern T, Laosuangkoon W, Tansangworn N. Atypical presentations of older adults at the emergency department and associated factors. Arch Gerontol Geriatr. 2016;62:97-102.

16. Grossman SA, Brown DFM, Chang Y, Chung WG, Cranmer H, Dan L, et al. Predictors of delay in presentation to the ED in patients with suspected acute coronary syndromes. Am J Emerg Med. 2003;21(5):425-8.

17. Vanpee D, Swine C, Vandenbossche P, Gillet JB. Epidemiological profile of geriatric patients admitted to the emergency department of a university hospital localized in a rural area. Eur J Emerg Med. 2001;8(4):301-4.

18. Nemec M, Koller MT, Nickel CH, Maile S, Winterhalder C, Karrer C, et al. Patients presenting to the emergency department with non-specific complaints: the Basel non-specific complaints (BANC) study. Acad Emerg Med Off J Soc Acad Emerg Med. 2010;17(3):284-92.

19. Quinn K, Herman M, Lin D, Supapol W, Worster A. Common diagnoses and outcomes in elderly patients who present to the emergency department with non-specific complaints. Cjem. 2015;17(5):516-22.

20. Smith SC, Carragher L. 'Just lie there and die': barriers to access and use of general practitioner out-of-hours services for older people in rural Ireland. Rural Remote Health. 2019;19(3):5088.

21. Coster JE, Turner JK, Bradbury D, Cantrell A. Why do people choose emergency and urgent care services? A rapid review utilizing a systematic literature search and narrative synthesis. Acad Emerg Med Off J Soc Acad Emerg Med. 2017;24(9):1137-49.

22. A full life - all your life. A Quality Reform for Older Persons Norwegian Ministry of Health and Care Services; 2019. [Available from: https://www. helsedirektoratet.no/tema/leve-hele-livet-kvalitetsreformen-for-eldre/inenglish-samegillii]. Accessed 15 Apr 2020.

23. Lov om kommunale helse- og omsorgstjenester Lovdata.no: Helse og omsorgsdepartementet; 2019. [Available from: https://lovdata.no/dokument/ NL/lov/2011-06-24-30]. Accessed 15 Apr 2020.

24. Langhelle A, Lossius HM, Silfvast T, Bjornsson HM, Lippert FK, Ersson A, et al. International EMS systems: the Nordic countries. Resuscitation. 2004;61 (1):921.

25. Nieber T, Hansen EH, Bondevik GT, Hunskar S, Blinkenberg J, Thesen J, et al. Organization of Norwegian out-of-hours primary health care services. Tidsskrift den Norske laegeforening. 2007;127(10):1335-8.

26. Huibers $L$, Giesen P, Wensing M, Grol R. Out-of-hours care in western countries: assessment of different organizational models. BMC Health Serv Res. 2009;9:105.

27. Midtbø V, Raknes G, Hunskaar S. Telephone counselling by nurses in Norwegian primary care out-of-hours services: a cross-sectional study. BMC Fam Pract. 2017;18(1):84.

28. Huibers LA, Moth G, Bondevik GT, Kersnik J, Huber CA, Christensen MB, et al. Diagnostic scope in out-of-hours primary care services in eight European countries: an observational study. BMC Fam Pract. 2011;12:30.

29. Hansen EH, Hunskaar S. Development, implementation, and pilot study of a sentinel network ("the watchtowers") for monitoring emergency primary health care activity in Norway. BMC Health Serv Res. 2008;8:62.

30. Raknes $G$, Hunskaar $S$. Reasons for encounter by different levels of urgency in out-of-hours emergency primary health care in Norway: a cross sectional study. BMC Emerg Med. 2017;17(1):19.

31. Cebicci H, Salt O, Gurbuz S, Sahin T, Cumaoglu MO, Koyuncu S. Atypical presentations of aortic dissections: a case series. Acta Medica Mediterranea. 2014;30(1):85-90.

32. van der Horst F, Metsemakers J, Vissers F, Saenger G, de Geus C. The reason-for-encounter mode of the ICPC: reliable, adequate, and feasible. Scand J Prim Health Care. 1989;7(2):99-103.

33. Norsk indeks for medisinsk nødhjelp (Norwegian Index of Emergency Medical Assistance). Helsedirektoratet (The Norwegian Directorate of Health). 2018. [Available from: https://www.helsedirektoratet.no/tema/ akuttmedisin]. Accessed 15 Apr 2020.

34. Palacios-Ceña D, Hernández-Barrera V, Jiménez-García R, Valle-Martín B, Fernández-de-las-Peñas C, Carrasco-Garrido P. Has the prevalence of health care services use increased over the last decade (2001-2009) in elderly people? A Spanish population-based survey. Maturitas. 2013;76(4):326-33.

35. Glynn LG, Valderas JM, Healy P, Burke E, Newell J, Gillespie P, et al. The prevalence of multimorbidity in primary care and its effect on health care utilization and cost. Fam Pract. 2011;28(5):516-23.

36. Moth G, Huibers L, Christensen MB, Vedsted P. Out-of-hours primary care: a population-based study of the diagnostic scope of telephone contacts. Fam Pract. 2016;33(5):504-9. 
37. O'Halloran J, Britt H. General practice encounters with older Australians. Australas J Ageing. 2004;23(1):7-12.

38. Helse hos eldre i Norge, Folkehelserapporten. Folkehelseinstituttet; 2018.

39. Zamora H, Clingerman EM. Health literacy among older adults: a systematic literature review. J Gerontol Nurs. 2011;37(10):41-51.

40. Kelly PA, Haidet P. Physician overestimation of patient literacy: a potential source of health care disparities. Patient Educ Couns. 2007;66(1):119-22.

41. Årsstatistikk fra legevakt 2018. Nasjonalt kompetansesenter for legevaktmedisin, NORCE Norwegian Research Centre; 2019.

42. Raknes G, Hansen EH, Hunskaar S. Distance and utilisation of out-of-hours services in a Norwegian urban/rural district: an ecological study. BMC Health Serv Res. 2013;13:222.

43. Arslanian-Engoren C. Gender and age bias in triage decisions. J Emerg Nurs. 2000;26(2):117-24.

44. Giesen PM, H. Ophey, G. Roeland, D. Grol, R. van den Bosch W. Hoe urgent is de gepresenteerde morbiditeit op de Centrale Huisartsenpost? Huisarts en Wetenschap 2005;48(5):673-677.

45. Canto JG, Rogers WJ, Goldberg RJ, Peterson ED, Wenger NK, Vaccarino V, et al. Association of age and sex with myocardial infarction symptom presentation and in-hospital mortality. JAMA. 2012;307(8):813-22.

\section{Publisher's Note}

Springer Nature remains neutral with regard to jurisdictional claims in published maps and institutional affiliations.

Ready to submit your research? Choose BMC and benefit from:

- fast, convenient online submission

- thorough peer review by experienced researchers in your field

- rapid publication on acceptance

- support for research data, including large and complex data types

- gold Open Access which fosters wider collaboration and increased citations

- maximum visibility for your research: over $100 \mathrm{M}$ website views per year

At $\mathrm{BMC}$, research is always in progress.

Learn more biomedcentral.com/submissions 